\section{OBRAS RELEVANTES}
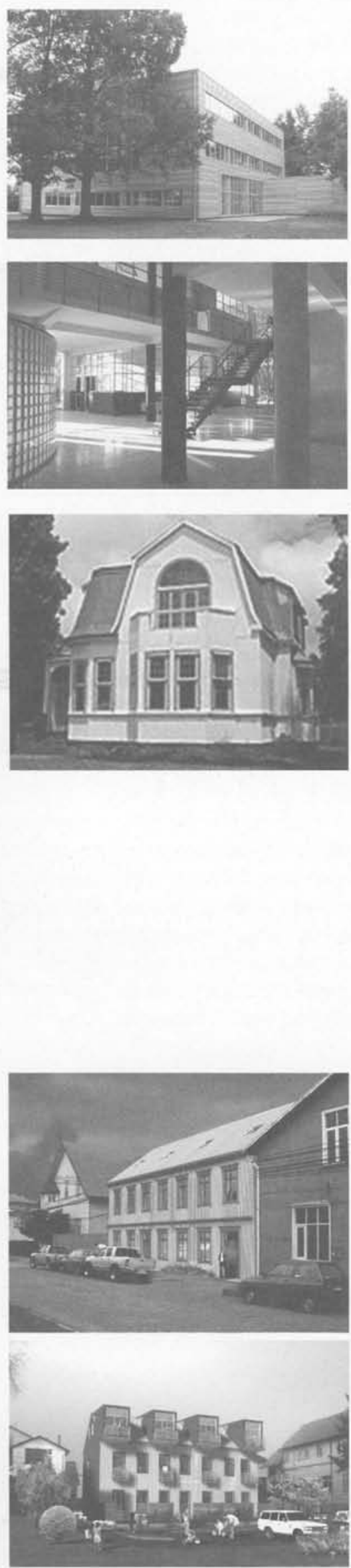

Nombre de la Obra: Edificio Facultad de Filosofia

Mandante: Universidad Austral de Chile

Arquitectos a cargo de Proyecto y Obra: Roberto Martínez y José Biskupovic Arquitectos Colaboradores: Carlos Willer, Cristian Valderrama, Carolina Ipinza Lugar: Campus Isla Teja, Valdivia, X Región.

Superficie Edificada: 1700 m2. Fecha de edificación: 2005

Destino: Educación Superior.

La Facultad de Filosofia y Humanidades de la UACh encarga un nuevo edificio, que se asume a través de dos condicionantes: el hermoso entorno de árboles y ríos y la complejidad programática. Se toma la opción arquitectónica de dividir el contenido de la envolvente. Un cuerpo simple puesto en la naturaleza, debía resolver de modo eficiente los diversos requerimientos programáticos. Se propone un galpón (arquetipo arquitectónico sureño) que dialoga con su entorno natural a través de color y textura. Éste es contenedor de la hibridación programática en torno a un vacío central, cuya atmósfera de meditación está inspirada en una paleta de colores orientales. Los programas del edificio están organizados en base a tres unidades programáticas principales. El confort térmico esta diseñado en base a una envolvente térmica que garantiza ahorro energético en invierno y los sistemas semi-pasivos de renovación de aire suplen el aire acondicionado proporcionando confortabilidad ambiental.

Nombre de la Obra: Museo Philippi, UACh, Traslado y remodelación de casa Schüler. Mandante: Universidad Austral de Chile

Arquitecta a cargo de Proyecto y Obra: Sofia Sanfuentes

Arquitecto Asesor: R.P Gabriel Guarda Geywitz O.S.B.

Lugar: Isla Teja,Valdivia, X Región.

Superficie Edificada: $470 \mathrm{~m} 2$.

Fecha de edificación: 1914, Traslado y remodelación 2005 - 2006 Destino: Museo Philippi

En enero de 2006 se inauguró la casa Schüler que albergará el Museo Philippi, emplazado en Isla Teja próximo al Museo Histórico y Arqueológico y de Arte Moderno de la Universidad Austral. Se trata del despiece, traslado y reconstrucción de la casa Schüler (construida en 1914 y de gran valor patrimonial) donada por un empresario privado a la Corporación del Patrimonio Cultural de Chile quien en conjunto con la Universidad Austral e instituciones públicas y privadas contribuyeron a la realización del proyecto. Es asi como la casa Schüler se constituye en uno de los elementos que consolidan el sector de museos de la ciudad. Desde un punto de vista de la sostenibilidad, cabe señalar dos hechos significativos como son la reutilización de una edificación existente adaptándola a un nuevo uso y la preservación del acerbo cultural arquitectónico de una ciudad con historia.

Nombre de la Obra: Lofts La Casona. Reciclaje Casa Lopetegui-Mena. Mandante: Socovesa.

Arquitecto responsable: Francisco Biskupovic Z.

Arquitecto colaborador y obra: Tirza Barria C.

Colaboradores: Renato Muñoz, Emilia Villagra, Roberto Flores, Pablo Schalscha, Cristian Manriquez, Jose Miguel Biskupovic.

Lugar: Calle General Lagos n ${ }^{\circ} 905$,Valdivia, X Región.

Superficie Edificada: 550 m2. Fecha de edificación: 1860, Reciclaje 2005 - 2006 Destino: Vivienda.

El desafio de este proyecto era salvar desde un punto arquitectónico y humanista, una de las últimas casas de mediados del siglo XIX. Después de una investigación histórica, aparecieron códigos arquitectónicos, comunes a varias casas que ya no existen, donde se reconoció la forma original; una matriz simple y rotunda tipo galpón, sobre la cual se trabajó restaurando 3 de sus fachadas y proponiendo un perfil nuevo hacia el rio; siendo necesaria la reinterpretación del mirador valdiviano. Este proyecto no es una restauración fidedigna, sino más bien, la recuperación de la memoria arquitectónica y de cómo a través de su reinvención, podemos traer a presencia este representante de la ciudad pasada a nuestra presente. 